\title{
Extragenital Müllerian Adenosarcoma in the Pouch of Douglas
}

\author{
Ateş Karateke ${ }^{1}$, İlker Kahramanoğlu², Remziye Bilgiç33 \\ ${ }^{1}$ Department of Gynecologic Oncology, Medical Park Hospital, İstanbul, Turkey \\ ${ }^{2}$ Department of Obstetrics and Gynecology, Süleymaniye Birth and Women Health Training and Research Hospital, İstanbul, Turkey \\ ${ }^{3}$ Department of Pathology, E-Sitopatoloji Pathology Laboratory, İstanbul, Turkey
}

Background: Extragenital Müllerian adenosarcomas are extremely rare tumours characterised by a stromal component of low-grade malignancy and by a benign glandular epithelial component.

Case Report: A 26-year-old woman was admitted to our clinic because of lower abdominal distension and left lower quadrant pain. Clinical and radiological examinations suggested an ovarian malignancy. Laparotomy revealed a cystic mass in the pouch of Douglas, originating from the left sacrouterine ligament. A total excision of the tumour was performed and showed low-grade adenosarcoma without sarcomatous overgrowth. Follow-up at 24 months after the surgery showed no evidence of recurrence.

Conclusion: Mullerian adenosarcoma located in the pouch of Douglas is rare. For treatment, success may be achieved with only excision of the tumour if there is no sarcomatous overgrowth or spread to adjacent tissues. (Balkan Med J 2014;31:100-104).

Key Words: Adenosarcoma, adnexal, Douglas, extragenital, Müllerian, tumour
Müllerian adenosarcoma is a mixed epithelial-mesenchymal neoplasm that originates from the Müllerian duct and is characterised by benign epithelial gland and malignant stromal components as active participants in the neoplastic process (1). The uterine corpus is the most common primary site but Müllerian adenosarcoma has been reported to arise in the ovary, cervix, vagina, pelvic peritoneum, pouch of Douglas, broad ligament, bladder, and colon (2-5). Although adenosarcomas are generally low-grade malignancies, adenosarcoma with sarcomatous overgrowth is a highly aggressive tumour. These tumours are frequently associated with postoperative recurrence or metastases and a fatal outcome, even in earlystage disease (6).

We present a case of Müllerian adenosarcoma located in the pouch of Douglas and report the clinical and pathological findings. This is the second case reported in the literature that was treated by total excision of the tumour, and no recurrence was seen during the subsequent 24-month period.

\section{CASE PRESENTATION}

A 26-year-old, gravida 0 , para 0 woman with lower abdominal distension and left lower quadrant pain was seen in our hospital. She had no significant medical or family history. Her menstruation cycles were regular and she had used no medica- tions. According to her history, she had no sexual relationship of any kind. Physical examination revealed a large, palpable mass in both lower quadrants up to the level of the umbilicus, with associated tenderness. Laboratory studies showed a minimally elevated cancer antigen 125 (CA-125) level of $36.2 \mathrm{U} /$ $\mathrm{mL}$. All other laboratory tests, including carcinogenic antigen (CA 19-9), carcinoembriogenic antigen (CEA), and alphafetoprotein (AFP) were within normal limits.

Transabdominal ultrasonography revealed a diffuse, free pelvic fluid and a complex adnexal multiloculated cystic mass measuring 10x8 cm, with solid areas and internal echoes.

One day later, computed tomography (CT) of the chest, abdomen, and pelvis demonstrated a $23 \times 11 \mathrm{~cm}$, solid/cystic mass arising in the left ovary with mural nodularity, which extended from the pelvis in the midline towards the umbilicus.

Magnetic resonance imaging (MRI) of the abdomen and pelvis was performed 3 days later. The MRI confirmed a predominantly solid left adnexal mass, which measured 15.4x11.2x1 cm (Figure 1). Both CT scan and MRI excluded any distant metastatic spread.

The patient underwent surgery with the presumed diagnosis of an ovarian malignancy. Laparotomy revealed an 18 $\mathrm{cm}$ cystic mass surrounded by a very thin wall in the pouch of Douglas. The mass was adherent to the sigmoid colon and the pelvic sidewall. Bilateral ovaries, the fallopian tubes, and upper abdomen appeared normal. The mass was removed 
completely from the left sacrouterine ligament, the left ureter was identified, intraoperative frozen section was performed, and a low-grade mesenchymal tumour was diagnosed. The surgery included omentectomy and peritoneal washing.

The gross pathological specimen of the mass was described as a multinodular predominantly solid mass with almost ping-pong ball-sized peripheral cystic areas (Figure 2). The solid component broke into the capsule as solid polypoid and papillary excrescences. Microscopically, the diagnosis of low-grade adenosarcoma without sarcomatous overgrowth was made (Figure 3), suggested that the mass arose from surface peritoneal endometriosis. Mitotic activity averaged 4-6

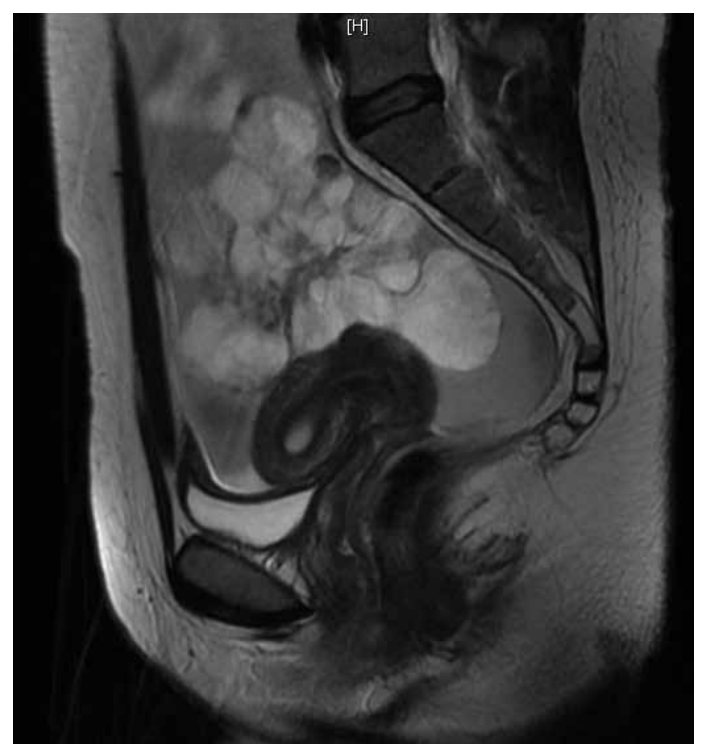

FIG. 1. Sagittal T2-weighted magnetic resonance image demonstrated a large heterogeneous predominantly solid mass, containing multiple papillary excrescences

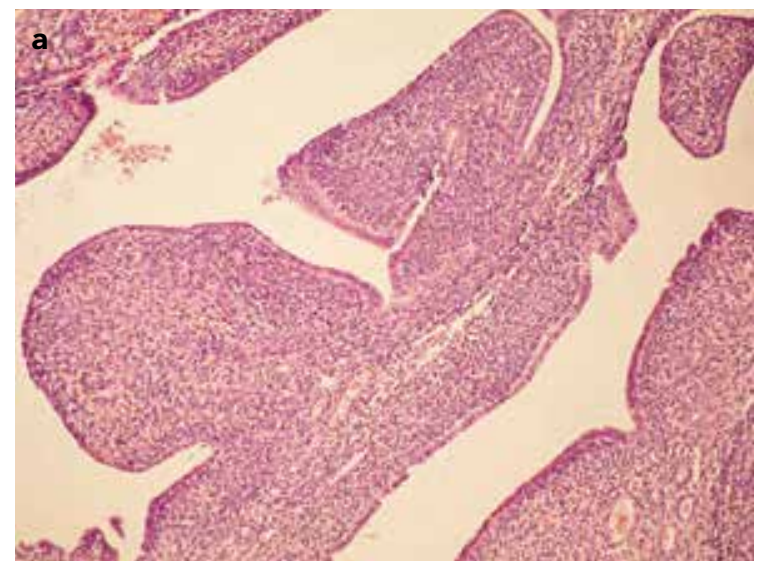

per 10 high-power fields (HPFs; x 400). No heterologous elements were seen. A baseline positron emission tomography (PET)/CT scan showed no FDG-avid intra-abdominal or retroperitoneal nodes or foci. No abnormal FDG-avid foci were noted in the liver, spleen, pancreas, or adrenal glands. Postoperatively, the patient did not receive chemotherapy. Follow-up at 24 months after surgery showed no evidence of recurrence.

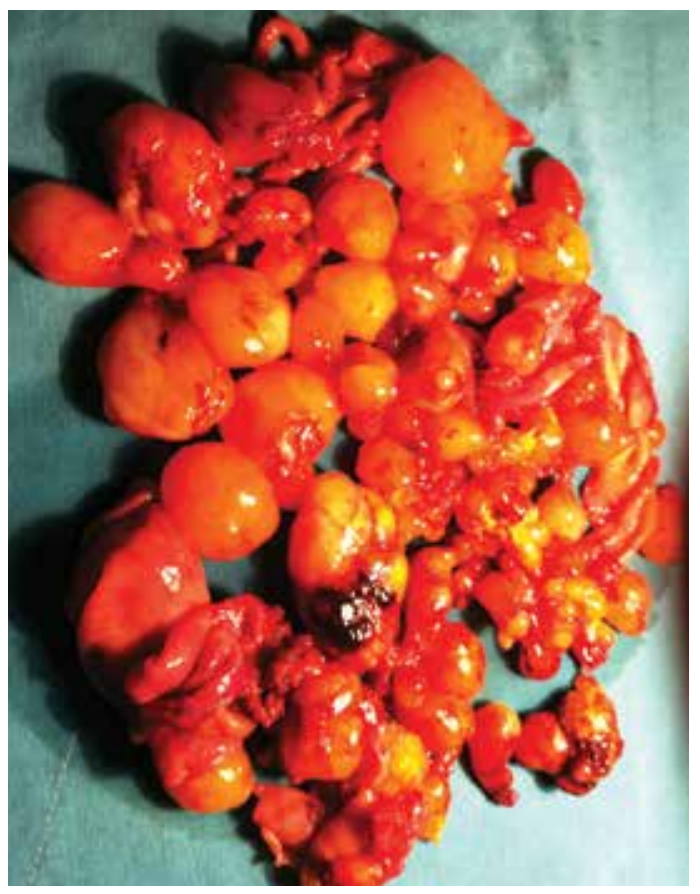

FIG. 2. Laparotomy revealed the mass in the lower abdomen, which originated from the left sacrouterine ligament and measured $18 \mathrm{~cm}$. The solid mass is covered by a cystic wall, which is seen as a pink tissue

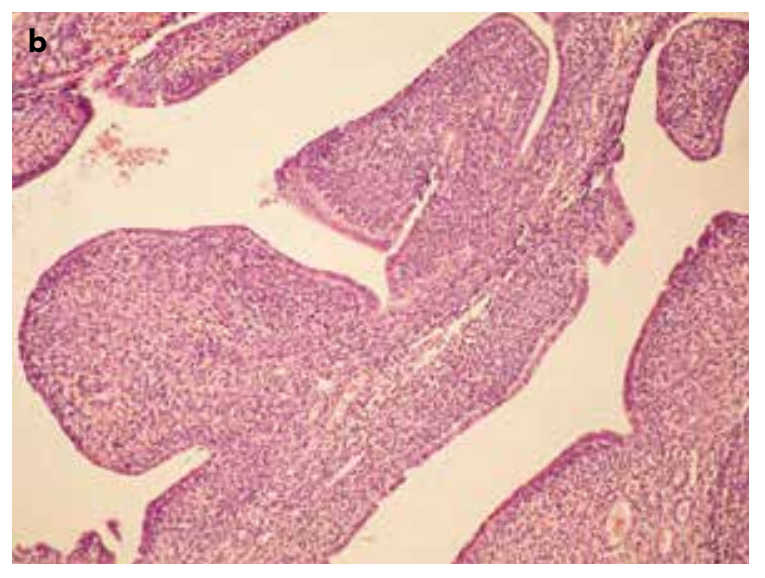

FIG. 3. a, b. Coexistence of the epithelial and stromal components. Benign appearing glandular structures form a 'leaf-like' pattern. Note the stromal hypercellularity. Haematoxylin and eosin, $100 \mathrm{x}$ magnification (a). The sarcomatous component showed scattered mitotic figures. Periglandular stromal cuffing is seen. Haematoxylin and eosin, $400 \times$ magnification (b) 
TABLE 1. Summary of cases of extragenital adenosarcoma until 2013, modified from Murugasu et al. (8)

\begin{tabular}{|c|c|c|c|c|c|}
\hline Authors & Age & Location & Clinical presentation & Treatment & Follow-up \\
\hline Douglas et al. (11) & 18 & Retroperitoneum & - & Chemo & $\begin{array}{l}\text { Died after } 10 \text { wks with distant } \\
\text { metastases }\end{array}$ \\
\hline Bard et al. (12) & 46 & Pelvic peritoneum & Pelvic pain & Sx, Chemo & $\begin{array}{l}\text { Died after } 11 \text { wks with distant } \\
\text { metastases }\end{array}$ \\
\hline Clement et al. (7) & 45 & Pelvic peritoneum & - & Sx, Rx & Pelvic recurrences; died after 9 months \\
\hline Clement et al. (7) & 73 & Pelvic peritoneum & - & Sx & Died after 2 months \\
\hline Clement et al. (7) & 58 & Pelvic peritoneum & - & Sx & $\begin{array}{l}\text { Local recurrence at } 15 \text { months; lung } \\
\text { metastases at } 45 \text { months }\end{array}$ \\
\hline Kao \& Norris (13) & 42 & Round ligament & - & $\begin{array}{l}\text { Partial Sx, } \\
\text { Chemo, Rx }\end{array}$ & Died of disease after 10 months \\
\hline Russell et al. (14) & 29 & Broad ligament & - & Sx, Rx & $\begin{array}{l}\text { Local recurrence at } 5 \text { months; } \\
\text { symptom-free; died of melanoma after } \\
9 \text { years }\end{array}$ \\
\hline Vara et al. (15) & 62 & Bladder & - & Sx & Disease-free at 1 year \\
\hline Roman et al. (16) & 63 & Retroperitoneum & - & Sx, Chemo, Rx & $\begin{array}{l}\text { Multiple recurrences; heart and liver } \\
\text { metastases; died of disease after } \\
10 \text { years }\end{array}$ \\
\hline Kerner et al. (17) & 32 & Broad ligament & - & Sx & Pelvic recurrences at 22 months \\
\hline De Jonge et al. (18) & 16 & Pelvic peritoneum & $\begin{array}{l}\text { Severe abdominal } \\
\text { distension and pain }\end{array}$ & Sx, Chemo & Disease-free at 57 months \\
\hline Kato et al. (19) & 20 & Peritoneum & Pelvic pain & Sx & Disease-free at 1 year \\
\hline Visvalingam et al. (3) & 50 & Pelvic peritoneum & $\begin{array}{l}\text { Painless abdominal } \\
\text { swelling of } 2 \text { months }\end{array}$ & Sx, Chemo & Died of disease after 1 year \\
\hline Ostor et al. (5) & 49 & Pouch of Douglas & Pelvic pain & Sx, Chemo, Rx & Alive with disease at 18 months \\
\hline Murugasu et al. (8) & 23 & Pouch of Douglas & Pelvic pain & Sx, Chemo, Rx & Disease-free at 1 year \\
\hline Huang et al. (10) & 41 & $\begin{array}{l}\text { The mesentery of } \\
\text { the terminal ileum, } \\
\text { the right colon, and } \\
\text { the pelvic sidewall }\end{array}$ & $\begin{array}{l}\text { Abdominal pain and } \\
\text { nausea }\end{array}$ & Sx, Chemo & $\begin{array}{l}\text { Ileal recurrence at } 1 \text { month; Chemo; } \\
\text { disease-free at } 18 \text { months }\end{array}$ \\
\hline Patrelli et al. (6) & 49 & Pouch of Douglas & Pelvic pain & $\begin{array}{l}\text { - First step: } \\
\text { partial surgery; } \\
\text { - Second step } \\
\text { (after } 24 \text { months): } \\
\text { radical surgery } \\
\text { and radiation } \\
\text { therapy }\end{array}$ & $\begin{array}{l}\text { Local multiple recurrences } \\
\text { (after } 18 \text { and } 24 \\
\text { months), today disease-free }\end{array}$ \\
\hline Present case & 26 & Pouch of Douglas & $\begin{array}{l}\text { Abdominal } \\
\text { distension and pain }\end{array}$ & $\begin{array}{l}\text { Total excision of } \\
\text { the tumour }\end{array}$ & Today disease-free \\
\hline
\end{tabular}

Wks: weeks; Chemo: chemotherapy; Sx: surgery; Rx: radiation therapy

\section{DISCUSSION}

Adenosarcoma was first described in 1974 as a mixed epithelial-mesenchymal tumour of a usually low-grade malignancy (1). Adenosarcoma is a rare tumour that accounts for $8 \%$ of malignant stromal tumours. Extrauterine adenosarcomas occur at a younger age (median age of 49 years) compared with uterine adenosarcomas (7).

Adenosarcoma should be histologically differentiated from its uterine counterpart, adenofibroma. Such histologies are similar to the presence of large areas of low cellularity and infrequent mitoses. Increased nuclear pleomorphism with a mitotic rate of two per HPF, distinctive periglandular cuffs of cellular stroma with or without intraglandular protrusions of stromal element, and invasion have been suggested as criteria for differentiating between these tumours (7). Both extrauterine and uterine adenosarcomas may have heterologous elements.

The major factor affecting the outcome is tumour location. The clinical behaviour of adenosarcoma differs based on the site of origin of the tumour. Extragenital tumours behave more aggressively, with recurrence in 50\% compared with $25 \%$ in uterine primaries. Haematogenous metastases occur in $33 \%$ of extragenital cases compared with $2 \%$ of uterine primaries. Mortality rates are $40 \%$ and $10 \%$ in extrauterine and 
uterine adenosarcomas, respectively (8-10). The reasons for the poorer prognosis of extragenital adenosarcoma have not been explored yet. Possible reasons are increased risk of local complications at extragenital sites such as bowel obstruction, increased size of tumours at presentation, and difficulty of providing complete surgical clearance in comparison with uterine primaries (8).

In addition, the degree of myometrial invasion and sarcomatous overgrowth (as defined by pure sarcoma without epithelial elements occupying at least $25 \%$ of the tumour) are the other negative prognostic factors $(6,8)$.

By contrast, associated endometriosis is a favourable prognostic factor in adenosarcoma patients (6). In their review, Huang et al. (10) suggested that the presence of endometriosis might confer a better prognosis in patients with extragenital adenosarcoma. Extragenital adenosarcoma may develop from malignant transformation of endometriosis or originate from multipotential pelvic mesothelial cells (7). In our case, even though foci of endometriosis were not identified before and during the surgery, areas of endometriosis were present on the pathology specimen. While endometrioid adenosarcoma is the second most common histotype among endometriotic lesions, it may not be a coincidence of endometriosis and the tumour in our case.

Some suggest that the therapeutic cornerstone is still radical surgery. A surgical approach similar to that used for the corresponding disease stages of endometrial carcinoma is recommended (14). However, there is no clear consensus about the type of surgery. In English literature, there are only four cases of extragenital adenosarcoma with a pouch of Douglas location. Local excision of tumour was performed in one case. After the 24-month follow-up of this pouch of Douglas-located case, local multiple recurrences were detected and radical surgery performed. Surgical treatment was supplemented by radiation therapy (6) (Table 1 ). In our case, because the patient was 26 , wished to preserve her fertility, and intraoperative frozen section diagnosis was low-grade adenosarcoma, we performed simple excision of the mass.

Some cases with uterine sarcoma respond to doxorubicinbased chemotherapy. Also, Huang et al. (10) observed a clinical response to doxorubicin chemotherapy in their patient and recommend the use of doxorubicin in all patients, especially those with extragenital adenosarcoma with sarcomatous overgrowth, due to the high risk of recurrence and death. Because of the diagnosis of low-grade adenosarcoma without sarcomatous overgrowth, we did not use chemotherapy for our patient. The interesting feature of this case is the fact that extrauterine adenosarcomas may be confused with ovarian malignancy on clinical and radiological examination.

There is no clear recommendation for treatment of extragenital adenosarcomas. Although disease recurrence occurs in over half of patients, no recurrence was seen in our patient. The presence of endometriosis and the absence of sarcomatous overgrowth might influence prognosis as favourable factors. However, long-term follow-up is needed. Because adenosarcoma may be seen in patients who wish to preserve their fertility, fertility-sparing surgery can be considered, especially if there is no sarcomatous overgrowth or spread to adjacent tissues.

Ethics Committee Approval: Ethics committee approval was received for this report.

Informed Consent: Written informed consent was obtained from patients who participated in this study.

Peer-review: Externally peer-reviewed.

Author contributions: Concept - A.K., İ.K.; Design - İ.K.; Supervision - A.K.; Resource - A.K., R.B.; Materials - R.B.; Data Collection\&/or Processing - İ.K., A.K.; Analysis\&/or Interpretation - A.K., İ.K.; Literature Search - İ.K.; Writing - İ.K., A.K.; Critical Reviews - A.K.

Conflict of Interest: No conflict of interest was declared by the authors.

Financial Disclosure: The authors declared that this study received no financial support.

\section{REFERENCES}

1. Clement PB, Scully RE. Müllerian adenosarcoma of the uterus. A clinicopathologic analysis of ten cases of a distinctive type of Müllerian mixed tumor. Cancer 1974;34:1138-49. [CrossRef]

2. Inoue M, Fukuda H, Tanizawa O. Adenosarcomas originating from sites other than uterine endometrium. Int J Gynaecol Obstet 1995;48: 299-306. [CrossRef]

3. Visvalingam S, Jaworski R, Blumenthal N, Chan F. Primary peritoneal mesodermal adenosarcoma: report of a case and review of the literature. Gynecol Oncol 2001;81:500-5. [CrossRef]

4. Toyoshima M, Akahira J, Moriya T, Hayakawa S, Yaegashi N. Primary vaginal adenosarcoma with sarcomatous overgrowth. Gynecol Oncol 2004;95:759-61. [CrossRef]

5. Ostör AG, Nirenberg A, Ashdown ML, Murphy DJ. Extragenital adenosarcoma arising in the pouch of Douglas. Gynecol Oncol 1994;53:373-5. [CrossRef]

6. Patrelli TS, Silini EM, Gizzo S, Berretta R, Franchi L, Thai E, et al. Extragenital Müllerian adenosarcoma with pouch of Douglas location. BMC Cancer 2011;15;11:171.

7. Clement PB, Scully RE. Extra uterine mesodermal (müllerian) adenosarcoma:a clinicopathologic analysis of five cases. Am J Clin Pathol 1978;69:276-83.

8. Murugasu A, Miller J, Proietto A, Millar E. Extragenital Mullerian adenosarcoma with sarcomatous overgrowth arising in an endometriotic cyst in the pouch of Douglas. Int J Gynecol Cancer 2003;13:371-5. [CrossRef]

9. Chang HY, Changchien CC, Chen HH, Lin H, Huang CC. Extrauterine Mullerian adenosarcoma associated with endometriosis and rectal villotubular adenoma: report of a case and review of the literature. Int $J$ Gynecol Cancer 2005;15:361-5. [CrossRef]

10. Huang GS, Arend RC, Sakaris A, Hebert TM, Goldberg GL. Extragenital adenosarcoma:A case report, review of the literature, and management discussion. Gynecol Oncol 2009;115:472-5. [CrossRef] 
11. Douglas GW, Kastin AJ, Huntington RW. Carcinoma arising in a retroperitonel Mullerian cyst with widespread metastases during pregnancy. Am J Obstet Gynecol 1965;91:210-6.

12. Bard E, Bard D, Vargas-Cortez F. Extrauterine Mullerian Adenosarcoma. A clinicopathologic report of a case with distant metastases and a review of the literature. Gynecol Oncol 1978;6:271-4. [CrossRef]

13. Kao GF, Norris HJ. Benign and low grade variants of mixed mesodermal tumour (6. adenosarcoma) of the ovary and adnexal region. Cancer 1978;42:1314-24. [CrossRef]

14. Russel P, Slavutin R, Laverty CR, Cooper J. Extrauterine mesodermal (Mullerian) adenosarcoma. A case report. Pathology 1979;11:557-60.[CrossRef]

15. Vara AR, Ruzics EP, Moussabeck O, Martin DC. Endometroid adenosarcoma of the bladder arising from endometriosis. J Urol 1990;143:813-5.
16. Roman LD, Mitchell MF, Tornos C, Glaver B, Kavanagh JJ. Dedifferentiated extrauterine adenosarcoma responsive to chemotherapy. Gynecol Oncol 1993;49:389-94. [CrossRef]

17. Kerner H, Lichtig C, Beck D. Extrauterine Mullerian adenosarcoma of the peritoneal mesothelium:a clinicopatholigic and electron microscopic study. Obstet Gynecol 1989;73:510-3.

18. De Jonge MJ, Van Dam PA, Van Marck E, Prove A, Van Oosterom AT. Primary extrauterine Mullerian adenosarcoma of the peritoneum. Gynecol Oncol 1995;57:126-30. [CrossRef]

19. Kato N, Zhe J, Endoh Y, Motoyama T. Extrauterine Mullerian adenosarcoma of the peritoneum with an extensive rhabdomyosarcomatous element and a marked myxoid change. Pathol Int 2000;50:347-51 [CrossRef] 